\title{
Comparative Fatty Acids Composition of Cashew, Fenugreek and Moringa Seed Oils
}

\author{
M. Alhassan", A. M. Bello, M. Suleiman, A. M. Safiya, A. A. Garba and \\ Y. Nasiru \\ Department of Chemistry, Sokoto State University, PMB 2134-Birnin Kebbi Road, Sokoto, Nigeria \\ *Corresponding author's e-mail: mansuralhassan@gmail.com
}

\begin{abstract}
Oil extraction from Cashew nut was carried out by Soxhlet method using n-hexane as the solvent. The oil was transesterified to produce Fatty Acid Methyl-Esters (FAMEs) and glycerol. Fenugreek and Moringa seed oils were purchased from the market. GCAnalysis gave the following fatty acids composition: Oleic (74.99\%), Linoleic $(1.27 \%)$, Stearic (2.09\%), Myristic (0.86\%), Lauric (1.97\%), Linolenic (1.75\%), Palmitic (12.51\%) and Palmitoleic (2.70\%) for Moringa oil; Oleic (67.62\%), Linoleic (16.99\%), Stearic $(8.42 \%)$ and Palmitic $(6.93 \%)$ for Cashew oil while Fenugreek oil constituted of Oleic (20\%), Linoleic $(42.5 \%)$, Stearic $(6.5 \%)$, Linolenic (18\%), Palmitic (10.5\%) and Arachidonic $(0.5 \%)$. The study revealed that the three vegetable seeds are good sources of edible oils. Cashew oil is considered to be the most suitable for food formulation as well as pharmaceutical, paint, soap and perfume industries because of high level of unsaturated in the fatty acid contents.
\end{abstract}

\section{Introduction}

Oil is any non-polar chemical substance that is viscous liquid at ambient temperature and is both hydrophobic (immiscible with water, literally water fearing) and lipophilic (miscible with other oil, literally fat loving). Oil has high carbon and hydrogen content and is usually flammable and surface active. Oils have always been an integral part of

Received: August 22, 2019; Accepted: October 31, 2019

Keywords and phrases: fatty acids, Fenugreek, Moringa, Cashew, oil extraction.

Copyright (C) 2019 M. Alhassan et al. This is an open access article distributed under the Creative Commons Attribution License, which permits unrestricted use, distribution, and reproduction in any medium, provided the original work is properly cited. 
human foods, being essential for health. Industrially, they play an important role in the development of different areas of chemical products, pharmaceutical, cosmetics, paints and most food [1-3].

Oils are naturally occurring esters of long straight-chain carboxylic acids. They belong to the saponification group (containing ester groups) of lipids. Lipids are biologically produced materials that are relatively insoluble in water but soluble in polar and non-polar organic solvents. Edible oils are constituted of triacylglycerol molecules, mainly formed by unsaturated (oleic, linoleic linolenic acids etc.) and saturated fatty acids (myristic, palmitic, stearic acids etc.) esterified to glycerol units [2]. They can be formed from a single fatty acid that could be esterified up to three times in to glycerol backbone, or at least by three different ones.

Fatty acid is a carboxylic acid with a long aliphatic chain which is either saturated or unsaturated. Most naturally occurring fatty acids have an unbranched chain of an even number of carbon atoms, from $\mathrm{C}_{4}$ to $\mathrm{C}_{28}$. Fatty acids are usually derived from triglycerides or phospholipids. Fatty acids are important dietary source of fuel for animals because, when metabolized, they yield large quantities of ATP. Many cell typed can use either glucose or fatty acids for this purpose. Long-chain fatty acids cannot cross the blood-brain (BBB) and so cannot be used as fuel by the cells of the central nervous system [3]. However, free short-chain fatty acids and medium-chain fatty acids can cross the blood-brain barrier in addition to glucose and ketone bodies.

Essential fatty acids, are fatty acids that humans and other animals must ingest because the body cannot synthesize them [2, 7]. Only two fatty acids are known to be essential for humans which are alpha-linolenic acid (an omega-3 fatty acid) and linoleic acid (an omega-6 fatty acid) as reported by Whitney et al. [4].

\subsection{Chemical composition of vegetable oils}

Although, triglycerides are the predominant component of most food fats and oils. The minor component however, includes mono and di-glycerides, free fatty acids, phosphatides, sterol, fatty alcohols, fat soluble vitamins, and other substances [2, 4].

A triglyceride is composed of glycerol and three fatty acids. When all the fatty acids in a triglyceride are identical, it is termed as 'simple' triglyceride. The most common forms however, are the 'mixed' triglyceride in which two or three kinds of fatty acids are present in the molecule $[4,8]$. 
Mono- and di-glycerides are mono and diesters of acid and glycerol they are used frequently in foods as emulsifiers. They are also prepared commercially by the reaction of glycerol and triglycerides or by the esterification of glycerol and fatty acids. While free fatty acids are unattached fatty acids present in a fat. Some unrefined oils may contain as much as several percent free fatty acids. The level of free fatty acids is reduced in the refining process. Refined fats and oils read for use as food usually have a near to nil free fatty acids content.

Phosphatides on the other hand, consist of alcohols (usually glycerol), combined with fatty acids, phosphoric acid, and a nitrogen containing compound for all practical purposes, refining removes the phosphatides from the fat and oil [2,9].

Although, sterols are found in both animal's fats and vegetable oils, there is a substantial difference biologically between those occurring in animal's fats and those present in vegetable oil. Cholesterol is the primary fat sterol and is only found in vegetable oil 'phytosterols', sitosterol and stigmasterol are the best known sterol vary with the source of the oil [3].

Fats and oils are very good sources of vitamin E. The fat-soluble vitamin A and D sometimes are added to foods which contain fat because they serve as good carrier and are widely consumed.

Tocopherols are important minor constituents of most vegetable fats. They serve as antioxidants to delay rancidity and as source of the essential nutrient vitamin E. The four tocopherol types, varying in antioxidation and vitamin E activityare alpha, beta gamma and delta tocopherols.

Carotenoids are colouring materials occurring naturally in fats and oils. The most range in colour from yellow to deep red. The level of most of these colour bodies are reduced during the normal processing of oil to give them acceptable colour, flavor, and stability AOAC, [5].

\subsection{Moringa oleifera, Cashew nut and Fenugreek oils}

Moringa oleifera, known as "Moringa" or "Malunggay" is an Indian tree that also grows in Asia, Africa, South-America, the Caribbean and Oceania. The oil extracted from Moringa is known as Ben oil and reputedly contains $70 \%$ of oleic acid, an 18carbon long monounsaturated fatty acid (MUFA). Since the oleic acids has good oxidative stability when compared with polyunsaturated fatty acids (PUFAs), it has 
found use in the food industry, as it allows for longer storage and high-temperature frying processing. It also has uses in medicine and water treatment [6].

According to Mani et al. [7] and Abdulkarim et al. [8], blending ben oil with sunflower oil and soybean oil enhances the oxidative stability of the mixture. Comparing the chemical properties, Moringa seed oil is considered equivalent to olive oil, and may be used for human consumption. Also, the oil from Moringa seeds has shown the strongest antifungal activity against a zoophilic dematophyte caused marked inflammatory reactions in humans.

Another potential use of Moringa oil is as biodiesel feedstock. As an alternative source of oil, Moringa seeds have been proposed as a potential source to complement the mentioned feedstock [9].

Cashew nut oil being delicious vegetable oil of high quality and one of the most widely used oil today, extracted by pressing the kernels or seed of the plant. The oil is extremely therapeutic for many reasons. Cashew tree has originated in Brazil and its fruits were broadly famous in this region. After this, Cashew also started growing in certain parts of Africa in addition to 56 continents of Asia. It is extremely well know that cashews are extremely abundant with selenium, zinc, magnesium, proteins as well as antioxidants.

According to Suárez-Mahecha [10] and Tinoco et al. [11], the essential linoleic fatty acid present in Cashew nut cannot be produced by the human body and therefore it has to be obtained from foods. The essential fatty acids are necessary for the proper functioning of the body and play important role in the regulation of several metabolic transport, and excretion processes.

Accordingly, Paiva et al. [12] and Ryan [13] reported that Cashew nut oil has a high nutritional value because it is rich in PUFAs (polyunsaturated fatty acids) since it contains oleic (w-9) (59-61\%) and linoleic (w-6) (16-20\%) fatty acids respectively.

Fenugreek (Trigonella foenum-graceum) is a self-pollinating annual herbaceous aromatic leguminous crop, widely cultivated in Northern Africa, Europe, West and South Asia, North America, Argentina and Australia. It is considered the oldest known medical plant in human history, reportedly used for the treatment of diabetes [14].

Fenugreek seed is a good source of essential amino acids, especially leucine, lysine and total aromatic amino acids. Recently, Savitha and Manohar [15] reported that the 
seed contains $20-25 \%$ protein, $6-8 \%$ oil, $45-50 \%$ dietary fiber, and $2-5 \%$ steroidal saponin. Further, the seed is well characterized with a distinctive pungent scent that impacts flavor, colour and aroma of foods, making it highly desirable in culinary applications as a food spices in countries where it is grown [16]. Advances in nutraceuticals and demand for functional foods have stimulated interest in Fenugreek as a food supplement. An increase in demand for food implies the need to increase the production of alternative sources of edible oils.

Studies conducted by Schuette et al. [17] focused on the health benefits of Fenugreek seed oil.

\section{Experimental}

\subsection{Sample procurement}

The Cashew nuts were obtained from Jega Local Government and Gotomo Village of Kebbi State while Moringa and Fenugreek oils were purchased from Sokoto Central market.

\subsection{Preparation of samples}

The Cashew nuts obtained were sun dried for two weeks, they were shelled in order to separate and obtain kernels free of cracks. This was done manually by placing them on a flat stone and cracked with a wooden mallet. The powder was stored and used for subsequent analysis.

\subsection{Oil extraction}

The Soxhlet column was fitted to a reflux condenser and the Soxhlet extractor set up was then placed on a boiling water bath. As the n-hexane vaporize and condense, condensed vapour falls into the porous thimble with contain the crushed powdered nut sample. The oil from the nut powder was then dissolved by n-hexane and forms a homogenous mixture.

The extraction was done continuously, changing the nut powder in the thimble after two hours, when most of the oil was expected to have been extracted. After extracting the oil, the homogenous mixture (i.e. oil/solvent) was transferred into a distillator, in order to separate the oil from n-hexane, the n-hexane distilled off and the oil was removed when all the suspected n-hexane was evaporated. The oil was then cooled after which it was weighted. 


\subsection{Determination of percentage oil yield}

The Franz Von Soxhlet extraction method described by AOAC [5], was used to determine the percentage oil yield. Five grams $(5.0 \mathrm{~g})$ of the powdered sample was placed in the thimble and about $150 \mathrm{ml}$ of normal hexane was poured into the round bottom flask. The apparatus was heated at about $600 \mathrm{C}$ for two hours continuous extraction. The experiment was repeated with 5.0g of sample. After two hours, solvent was distilled and the percentage oil yield determined.

$$
\% \text { Oil Content }=\frac{\text { Weight of oil extracted }}{\text { Weight of the seed }} \times 100 .
$$

\subsection{Transesterification}

Transesterification is a reaction of triglyceride with alcohol to produce esters and glycerol. The reaction is often catalyzed by an acid, base or enzymes. Base catalyzed reaction is employed for oils having low free fatty acids content [18].

The method of Alhassan et al. [19] was employed for the oil transesterification. The oil samples $\left(25 \mathrm{~cm}^{3}\right)$ each was dissolved in toluene $(1 \mathrm{ml})$ in a test tube fitted with a condenser, and $1 \%$ sulphuric acid in methanol $(2 \mathrm{ml})$ is added. The mixture was left over night in stoppered tube at $50^{\circ} \mathrm{C}$ (or is refluxed for 2 hours), then water $(5 \mathrm{ml})$ containing sodium chloride $(5 \%)$ is added and the required esters are extracted with hexane, using Pasteur pipette to separate the layers. The hexane layer was washed with water $(4 \mathrm{ml})$ containing potassium bicarbonate $(2 \%)$ and dried over anhydrous sodium sulphate. The solution is filtered and the solvent removed under reduced pressure in a rotatory film evaporator or in a stream of nitrogen. The same procedure was employed for all the oil samples.

\subsection{Determination of fatty acid profile of the oil}

Fatty acids profile of the oils were determined using gas layer chromatography, methyl ester derivatives were first prepared by transesterification as stated elsewhere [18].

\section{Results}

The results obtained from the experimental studies are presented in Tables 1-2. 
Table 1. Prevalent fatty acids composition in the three oils.

\begin{tabular}{lllll}
\hline Fatty Acids & Formula & C/O $(\%)$ & F/O $(\%)$ & M/O (\%) \\
Lauric acid & $\mathrm{C}_{12: 0}$ & --- & --- & 1.97 \\
Myristic acid & $\mathrm{C}_{14: 0}$ & --- & --- & 0.86 \\
Palmitic acid & $\mathrm{C}_{16: 0}$ & 6.93 & 10.5 & 12.51 \\
Stearic acid & $\mathrm{C}_{18: 0}$ & 8.42 & 6.5 & 2.09 \\
Oleic acid & $\mathrm{C}_{18: 1}$ & 67.62 & 20.0 & 74.99 \\
Linoleic acid & $\mathrm{C}_{18: 2}$ & 16.99 & 42.5 & 1.27 \\
Arachidonic acid & $\mathrm{C}_{20: 0}$ & --- & 0.5 & --- \\
Linoleic acid & $\mathrm{C}_{18: 3}$ & --- & 18.0 & 1.75 \\
Palmitoleic acid & $\mathrm{C}_{16: 0}$ & --- & -- & 2.70 \\
\hline
\end{tabular}

Keywords: F/A: Fatty Acid, C/O: Cashew Oil, F/O: Fenugreek Oil, M/O: Moringa Oil.

Table 2. Percentage unsaturated/saturated fatty acids in the three oils.

\begin{tabular}{llll} 
Sample/Oil Type & TSFAs $(\%)$ & TUFAs $(\%)$ & Others $(\%)$ \\
Moringa & 20.13 & 78.09 & 3.83 \\
Fenugreek & 17.51 & 80.5 & 2 \\
Cashew nut & 15.35 & 84.61 & 0.04 \\
\hline
\end{tabular}

Keywords: TSFAs $=$ Total Saturated Fatty Acids; TUFAs $=$ Total Unsaturated Fatty Acids .

\section{Discussion}

Table 1 presents the percentage fatty acid compositions in the three oils. The fatty acid composition which is the mixture of triglycerides is a characteristic to each vegetable oil. The Cashew, Moringa and Fenugreek oils have high content of monounsaturated fatty acids (MUFAs) Oleic acid 67.62\%, 20\%, 74.99\% respectively. The levels of linoleic acid in oils studied are low; (16.99\%) for Cashew oil and (1.27\%) for Moringa oil. 
On the other hand, Fenugreek oil contain higher amount of Linoleic acid (42.5\%) while Linolenic acid, Oleic acid and Palmitic acid contents are found to be 18\%, 20\%, $10.5 \%$ respectively. Beside these fatty acids, the oil also contain small amount of Stearic acid (6.5\%) and Arachidonic acid (2.5\%). Moreover, the amount of the Linoleic acid detected in both plant seed oils were comparable to many seeds such as Cucurbia maxima (43-50.3\%) as Gyroperma (35.6-45.3\%) reported by Applequist et al. [20]. It has been reported by Prasad [16], that Fenugreek (Hulba) is useful in flavoring many canned food and syrups and as an ingredient in some perfumes.

The prevalent fatty acids found in Cashew nut oil were Palmitic acid (6.93\%), Linoleic acid (16.99\%), Oleic acid (67.62\%) and Stearic acid (8.42\%). Unlike Fenugreek, Cashew nut has a content of both monounsaturated (MUFAs) and polyunsaturated fatty acids (PUFAs), which amounted to $67.62 \%$ and $16.99 \%$ respectively. Mexis and Kontominas [21] reported a lower value (50\%) for (MUFAs) in Cashew nut oil.

Lauric acid, Myristic acid, Palmitic acid and Palmitoleic acid were the saturated fatty acids in Moringa oil and there percentages were 1.97\%, $0.86 \%, 12.51 \%$ and $2.70 \%$ respectively.

The total unsaturated fatty acid is seen to be much higher than the total saturated fatty acids in Cashew, Moringa and Fenugreek oils. This agrees with the report of Wardlaw [22] that the plant oil contains mostly unsaturated fatty acids from 73-94\% of the total lipids. From nutritional viewpoint, the presence of Oleic acid in diet is very useful. It has been reported [23-27] that Oleic acid is effective in lowering the total cholesterol (10\%) in blood.

Therefore it is useful in reducing cardiovascular diseases like atherosclerosis [2835]. The slight differences in the values obtained in this work and from those reported elsewhere in literature may be due to differences in environment, genetic and geographical factors [36].

The presence of saturated and unsaturated fatty acids in the oils, projects the oils for use in food industry, soap industry and coating industry after consideration of other important qualities/characteristic relevant to usage [37-39]. 


\section{Conclusion}

In view of these findings about Cashew oil, Moringa oil and Fenugreek oil, it can be concluded that the oils can be used in food. Other areas of importance are soap, paint and pharmaceutical industries.

The improvement on the oil yield capacity of the Cashew may be through genetic modification and will be an exciting future challenge thus will form our next line of research effort.

\section{References}

[1] A. M. E. Suleiman, A. O. Ali and J. Hemavathy, Lipid content and fatty acid composition of fenugreek (Trigonellafoenum-gracum L.) seeds grown in Sudan, International Journal of Food Science and Technology 43 (2008), 380-382. https://doi.org/10.1111/j.1365-2621.2006.01446.x

[2] Robert S. Goodhart and Maurice E. Shils, Modern Nutrition in Health and Disease, 6th ed., Philadelphia: Lea and Febiger, 1999.

[3] A. Tsuji, Small molecular drug transfer across the blood-brain barrier via carrier-mediated transport systems, Neurotherapeutics 2 (2005), 54-62. https://doi.org/10.1007/BF03206642

[4] E. Whitney and S. R. Rolfes, Understanding Nutrition, 11th ed., Belmont: Thomson Higher Education, 2008.

[5] Association of Official analytical Chemists (AOAC), Official Methods of Analysis, 12th ed., Washington DC, 2000.

[6] S. C. Verma, R. Banerji, G. Misra and S. K. Nigam, Nutritional value of Moringa, Curr. Sci. 45 (1976), 769-770.

[7] S. Mani, S. Jaya and R. Vadivambal, Optimization of solvent extraction of moringa (Moringa oleifera) seed kernel oil using response surface methodology, Food and Bioproducts Processing 85 (2007), 328-335. https://doi.org/10.1205/fbp07075

[8] S. M. Abdulkarim, K. Long, O. M. Lai, S. K. S. Muhammad and H. M. Ghazali, Frying quality and stability of high-oleic seed oil in comparison with other vegetable oils, Food Chemistry 105(4) (2007), 1382-1389. https://doi.org/10.1016/j.foodchem.2007.05.013

[9] Jessica Ortiz Palafox, Abelardo Navarrete, Julio C. Sacramento-Rivero, Carlos RubioAtoche, Pablo Acereto Escoffie, Jose Antonio Rocha-Uribe, Extraction and 
characterization of oil from Moringa oleifera using supercritical $\mathrm{CO}_{2}$ and traditional solvents, American Journal of Analytical Chemistry 3 (2012), 946-949.

http://dx.doi.org/10.4236/ajac.2012.312A125

[10] Héctor Suárez-Mahecha, Alicia de Francisco, Luiz Henrique Beirão, Jane Mara Block, Adriana Saccol and Sandra Pardo-Carrasco, Importância de ácidos graxos poliinsaturados presentes em peixes de cultivo e de ambiente natural para a nutrição humana, Boletim do Instituto de Pesca 28 (2002), 101-110.

[11] Sandra Manzato Barboza Tinoco, Rosely Sichieri, Anibal Sanchez Moura, Flávia da Silva Santos and Maria das Graças Tavares do Carmo, Importância dos ácidos graxos essenciais e os efeitos dos ácidos graxos trans do leite materno para o desenvolvimento fetal e neonatal, Cadernos de Saúde Pública 23 (2007), 525-534.

https://doi.org/10.1590/S0102-311X2007000300011

[12] F. F. de A. Paiva, D. dos S. Garrutti and R. M. da Silva Neto, Aproveitamento Industrial do Caju, fortaleza: embrapaagroindustia Tropical,88, 2000.

[13] E. Ryan, K. Galvin, T. P. O'Connor, A. R. Maguire and N. M. O.Brien, Fatty acid profile, tocopherol, squalene and phytosterol content of brazil, pecan, pine, pistachio and cashew nuts, International Journal of Food Sciences and Nutrition 57(3-4) (2006), 219-228. https://doi.org/10.1080/09637480600768077

[14] Ling-Biao Gu, Xiao-Ning Liu, Hua-Min Liu, Hui-Li Pang and Guang-Yong Qin, Extraction of fenugreek (Trigonella foenum-graceum L.) seed oil using subcritical butane: characterization and process optimization, Molecules 22 (2017), 228. https://doi.org/10.3390/molecules22020228

[15] H. G. Savitha and B. Manohar, Studies on grinding and extraction of oil from fenugreek (Trigonella foenum-graecum) seed, International Journal of Food and Engineering 11 (2015), 275-283. https://doi.org/10.1515/ijfe-2014-0262

[16] R. Prasad, Identification of High Seed yielding and stable fenugreek mutants, Masters Thesis, University of Lethbridge, Lethbridge, AB Canada, 2014.

[17] H. A. Schuette, M. A. Cowley, H. A. Vogel and M. M. Mueller, Fenugreek seed oil, Oil Soap 17 (1940), 122. https://doi.org/10.1007/BF02542874

[18] R. Garces, and M. Mancha, One-step lipid extraction and fatty acid methyl esters preparation from fresh plant tissues, Analytical Biochemistry 211 (1993), 139-143. https://doi.org/10.1006/abio.1993.1244

[19] K. J. Umar, M. Alhassan, T. I. Ahmad, S. A. Zauro, N. A. Sani, A. M. Lawal and L. G. Hassan, The proximate, mineral and fatty acids profile of white grubs (Scrabidae), African Journal of Natural Sciences 15 (2012), 7-11 
[20] Wendy L. Applequist, Bharathi Avula, Brian T. Schaneberg, Yan-Hong Wang and Ikhlas A. Khan, Comparative fatty acid content of seeds of four Cucurbita species grown in a common (shared) garden, Journal of Food Composition and Analysis 19 (2006), 606-611. https://doi.org/10.1016/j.jfca.2006.01.001

[21] S. F. Mexis and M. G. Kontominas, Effects of $\gamma$-irradiation on physicochemical and sensory properties of cashew nuts (Anacardium occidentale L.), Food Science And Technology 42 (9) (2009) 1501-1507. https://doi.org/10.1016/j.lwt.2009.03.023

[22] G. M. Wardlaw, Contemporary Nutrition, 5th ed., New York: McGraw Hill Higher Education, 2003, pp. 143-159.

[23] Dennys E. C. Cintra, André G. V. Costa, Maria do Carmo G. Peluzio, Sérgio L. P. Matta, Marco Túlio C. Silva and Neuza M. B. Costa, Lipid profile of rats fed high-fat diets based on flaxseed, peanut, trout, or chicken skin, Nutrition 22 (2006), 197-205. https://doi.org/10.1016/j.nut.2005.09.003

[24] Lisa L. Dean, Jack P. Davis and Timothy H. Sanders, Groundnut (Peanut) Oil, in: Frank D. Gunstone, ed., Vegetable Oils in Food Technology: Composition, Properties and Uses, 2011. https://doi.org/10.1002/9781444339925.ch8

[25] Gillian Butler, Jacob H. Nielsen, Tina Slots, Chris Seal, Mick D. Eyre, Roy Sanderson and Carlo Leifert, Fatty acid and fat-soluble antioxidant concentrations in milk from highand low-input conventional and organic systems: seasonal variation, Journal of the Science of Food and Agriculture 88 (2008), 1431-1441. https://doi.org/10.1002/jsfa.3235

[26] W. S. Harris, n-3 fatty acids and serum lipoproteins: human studies, The American Journal of Clinical Nutrition 65(5) (1997), 1645S-1654S.

https://doi.org/10.1093/ajcn/65.5.1645S

[27] S. M. Grundy, Monounsaturated fatty acids and cholesterol metabolism: implications for dietary recommendations, J. Nutr. 119 (1989), 529-533.

[28] R. E. Heinig, The patient with diabetes: preventing cardiovascular complications, Clinical Cardiology 29(52) (2006), 13-20. https://doi.org/10.1002/clc.4960291404

[29] Stavros Lalas and John Tsaknis, Characterization of Moringa oleifera seed oil variety “'Periyakulam 1" Journal of Food Composition and Analysis 15 (2002), 65-77. https://doi.org/10.1006/jfca.2001.1042

[30] R. C. Badami and G. S. Kalburgi, Component acids of Trigonella Foenumgraecum (Fenugreek) seed oil, The Karnatak University Journal Sciences 14 (1969), 16-19.

[31] G. M. S. El-Bahy, FTIR and Raman spectroscopic study of Fenugreek (Trigonella foenum 
graecum L.) seeds, Journal of Applied Spectroscopy 72 (2005), 111-116.

https://doi.org/10.1007/s10812-005-0040-6

[32] M. Arivalagan, K. K. Gangopadhyay and G. Kumar, Determination of steroidal saponins and fixed oil content in fenugreek (Trigonella foenum-graecum) genotypes, Indian Journal of Pharmaceutical Sciences 75 (2013), 110-113.

https://doi.org/10.4103/0250-474X.113542

[33] M. Madhava Naidu, B. N. Shyamala, J. Pura Naik, G. Sulochanamma and P. Srinivas, Chemical composition and antioxidant activity of the husk and endosperm of fenugreek seeds, Food Science and Technology 44 (2011), 451-456.

https://doi.org/10.1016/j.lwt.2010.08.013

[34] B. S. Ogunsina, T. N. Indira, A. S. Bhatnagar, C. Radha, S. Debnath, A. G. Gopala Krishna, Quality characteristics and stability of Moringa oleifera seed oil of Indian origin, Journal of Food Science and Technology 51 (2014), 503-510.

https://doi.org/10.1007/s13197-011-0519-5

[35] P.-H. Chuang, C.-W. Lee, J.-Y. Chou, M. Murugan, B.-J. Shieh and H.-M. Chen, Antifungal activity of crude extracts and essential oil of Moringa oleifera Lam, Bioresource Technology 98 (2007) 232-236. https://doi.org/10.1016/j.biortech.2005.11.003

[36] C. Ramachandran, K. V. Peter and P. K. Gopalakrishnan, Drumstick (Moringa oleifera): A multipurpose Indian vegetable, Economic Botany 34 (1980), 276-283. https://doi.org/10.1007/BF02858648

[37] A. F. S. Santos, A. C. C. Argolo, L. C. B. B. Coelho and P. M. G. Paiva, Detection of water soluble lectin and antioxidant component from Moringa oleifera seeds, Water Resources 39 (2005), 975-980. https://doi.org/10.1016/j.watres.2004.12.016

[38] Anne C. M. Thiébaut, Véronique Chajès, Mariette Gerber, Marie-Christine BoutronRuault, Virginie Joulin, Gilbert Lenoir, Franco Berrino, Elio Riboli, Jacques Bénichou, Françoise Clavel-Chapelon, Dietary intakes of omega-6 and omega-3 polyunsaturated fatty acids and the risk of breast cancer, International Journal of Cancer 124 (2009), 924931. https://doi.org/10.1002/ijc. 23980

[39] J. Tsaknis, S. Lalas, V. Gergis and V. Spiliotis, A total characterization of Moringa oleifera Malawi Seed Oil, La Rivista Italiana delle Sostanze Grasse 75 (1998), 21-28. 